\title{
Analyst
}

Cite this: Analyst, 2014, 139, 1953

\section{Novel method of screening the oxidation and reduction abilities of photocatalytic materials $\uparrow$}

\author{
K. Katayama, ${ }^{\text {*a }}$ Y. Takeda, ${ }^{a}$ K. Shimaoka, ${ }^{a}$ K. Yoshida, ${ }^{a}$ R. Shimizu, ${ }^{a}$ T. Ishiwata, ${ }^{a}$ \\ A. Nakamura, ${ }^{a}$ S. Kuwahara, ${ }^{a}$ A. Mase, ${ }^{b}$ T. Sugita ${ }^{b}$ and M. Mori ${ }^{b}$
}

Two analytical methods for the evaluation of photocatalytic oxidation and reduction abilities were developed using a photocatalytic microreactor; one is product analysis and the other is reaction rate analysis. Two simple organic conversion reactions were selected for the oxidation and reduction. Since the reactions were one-to-one conversions from the reactant species to the product species, the product analysis was simply performed using gas chromatography, and the reactions were monitored in situ in the photocatalytic microreactor using the UV absorption spectra. The partial oxidation and reduction abilities for each functional group can be judged from the yield and selectivity, and the corresponding reaction rate, while the total oxidation ability can be judged from the conversion. We demonstrated the application of these methods for several kinds of visible light photocatalysts.

Received 26th November 2013 Accepted 11th January 2014

DOI: 10.1039/c3an02167j

www.rsc.org/analyst photocatalytically generated intermediate radical species were also observed. ${ }^{5,17,18}$

In recent years, the demand for visible light responsive materials has been increasing, and many papers on the development of new materials have been published. This is not only for organic decomposition, but also for generation of solar fuels and light harvesting applications. ${ }^{19-21}$ Although the development of materials has been intensively explored, the analytical methods for understanding the abilities of the materials have not changed. Typical methods of examining photocatalytic materials are the color degradation of methylene blue in aqueous solutions $\mathrm{s}^{22,23}$ and the decomposition of acetaldehyde under ambient conditions, ${ }^{24}$ defined in the Japanese Industrial Standard (JIS). These methods give information on total oxidation ability. There is another promising method, where the oxidation of dimethylsulfoxide is observed by ion chromatography. ${ }^{25}$ Since methyl groups are replaced with hydroxyl radicals in a stepwise manner, the obtained products provide direct information on the hydroxyl radical activity.

From our point of view, the analytical methods for photocatalysts are not sufficient to cover many recently developed materials, which may have other potential applications. The problems with the conventional analytical methods are as follows: (1) under aqueous or ambient conditions, various AOSs, depending on the experimental conditions $(\mathrm{pH}$, humidity, coexisting species), are involved in photodecomposition, and it is difficult to determine which one is the actual cause of the reaction; (2) methylene blue is not a good test material for dye degradation because it is subject to multi-point reactions in the molecule at the same time, as we clarified in a previous study, ${ }^{26}$ and the color degradation does not necessarily reflect the total oxidation ability.
${ }^{a}$ Department of Applied Physics, Chuo University, 1-13-27 Kasuga, Bunkyo, 112-8656, Tokyo, Japan

${ }^{b}$ Graduate School of Engineering, Gunma University, 1-5-1 Tnejin-cho, Kiryu, Gunma 376-8515, Japan

$\dagger$ Electronic supplementary information (ESI) available: Experimental setups are given in Fig. S1-S3. Examples of the fitting of the UV spectra using the reference spectra of the reactants and products are given in Fig. S4. See DOI: 10.1039/c3an02167j 
We recently developed a spectroscopic monitoring system for photocatalytic reactions using a microreactor ${ }^{26}$ to reduce the reaction time, and successfully accomplished the quick monitoring of a photocatalytic reaction in a capillary. There are also several other reports on the decrease in reaction time by utilizing microreactors in photocatalytic reactions. ${ }^{27-32} \mathrm{We}$ studied the reaction mechanisms for various dyes composed of different main structures, and we successfully performed a kinetic analysis and clarified multi-step reactions, self-catalytic reactions, and more complicated reactions by monitoring the intermediate species involved in each reaction. The results suggested that typical analyses based on the quasi-first-order or Langmuir-Hinshelwood mechanisms ${ }^{33,34}$ are not sufficient to clarify the reaction processes correctly. Furthermore, we proposed a new concept of a photocatalytic microreactor, in which no electrical resources are necessary to perform the photocatalytic reaction due to the use of a natural force such as capillary force or diffusion due to the concentration gradient, and successfully demonstrated its use in our previous paper. ${ }^{35}$

In this study, we propose a new methodology to clarify the actual abilities of photocatalytic materials, by obtaining the selective oxidation, reduction and total oxidation abilities and the corresponding reaction rates through simple screening methods using a photocatalytic microreactor. We performed some of the oxidation and reduction reactions in organic solvents, not in water, to avoid complex reactions involving various AOSs. By analysing the simple oxidation and reduction reactions, the electron or hole donation abilities can be understood. We applied two methods for these reactions; one is product analysis to obtain the conversion, yield and selectivity, giving information on the total oxidation, partial oxidation and reduction abilities, and the other is reaction rate analysis by monitoring the reaction directly inside the microreactor using UV spectra.

\section{Experimental}

For the product analyses, photocatalytic reactions were performed using the automatic photocatalytic reactors we developed in our previous paper. ${ }^{35}$ The principle is briefly explained as follows (Fig. S1†): photocatalytic microreactors were prepared by coating photocatalytic materials inside a capillary with both ends open. Six capillaries were bundled together and the bottoms were soaked in a reagent solution inside a test tube. Due to the capillary force, several centimeters of the solution entered the capillaries, and UV or visible light irradiation was used to induce the reaction. Since the reactant was decomposed by light irradiation, a concentration gradient formed inside the microreactors, driving the reactants beneath the capillary bundle into the microreactors due to diffusion, and vice versa for the products. The reaction then continued until the concentration gradient disappeared; thus, all of the reactants were reacted.

The photocatalyst was coated inside a fused silica capillary (I.D. $1.1 \mathrm{~mm}$, O.D. $1.4 \mathrm{~mm}$ ) with a length of $6 \mathrm{~cm}$. The capillary was transparent, and was treated using an alkaline solution before coating. The capillary was soaked in paste, filled with the solution three times, and heated to $450{ }^{\circ} \mathrm{C}$ in a furnace for $1 \mathrm{~h}$. Six capillaries were bundled together, and were placed in a test tube containing a reactant solution $(1 \mathrm{~mL})$. Due to the capillary force, the reactant solution typically rose a few centimeters above the solution surface.

The test tubes were loaded onto a merry-go-round type photoreaction stage with 8 test tube holders (Fig. S2 $\dagger$ ), and a light was shone from the side at a distance of about $10 \mathrm{~cm}$, typically for $18 \mathrm{~h}$. The reaction time was decided in advance by checking the necessary reaction time for $1 \mathrm{~mL}$ of a reactant solution with 6 photocatalytic microreactors. A UV-LED with a wavelength of $365 \mathrm{~nm}$ and an intensity of $360 \mathrm{~mW} \mathrm{~cm} \mathrm{~cm}^{-2}$ was used as a UV source, and a quasi sunlight source (XC-100, Solax) was used as a visible light source. After the reaction, the solution was analysed using gas chromatography (Shimadzu, GC-2014) and GC mass spectrometry (Agilent, 6890N(GC), 5975B (inert XL El/Cl MSD)).

For the reaction rate analysis, a reaction monitoring system was used (Fig. S3†), which was developed in our previous paper for studying the dye degradation processes. ${ }^{26}$ Some modifications were made to measure the UV spectra of simple organic molecules. The light source was a deuterium lamp (D2), and a UV spectrometer (Ocean optics, USB4000) covering a wavelength range of 220-400 $\mathrm{nm}$ was used. The capillary used for the photocatalytic microreactor was made of fused silica with a diameter of $500 \mu \mathrm{m}$.

The solution was injected into the capillary using a syringe pump. After the flow stopped, we waited for $c a$. 30 seconds until adsorption equilibrium was reached. The photocatalytic reaction was initiated by light irradiation from the top side. The light sources were UV-LEDs at $365 \mathrm{~nm}$ and $450 \mathrm{~nm}$ for UV photocatalysts and visible light photocatalysts, respectively. Perpendicular to the light, a fiber tip connected to the D2 lamp was placed at the reaction location. The other end of the fiber tip was placed on the opposite side of the D2 lamp, and the absorption spectrum was monitored with a spectrometer. The intensity of the D2 lamp was adjusted so as not to induce photoreactions or photocatalytic reactions.

As a typical photocatalyst, $\mathrm{TiO}_{2}$ powder (P25, average diameter $(D): 21 \mathrm{~nm})$ was used. It was mixed with water $(3.33 \mathrm{~mL})$ and acetylacetone $(0.33 \mathrm{~mL})$ in a mortar for $30 \mathrm{~min}$, to prepare a $\mathrm{TiO}_{2}$ paste. A tungsten oxide coating solution (Toshiba materials, SJ9003-1, D: ca. $100 \mathrm{~nm})$, nitrogen doped titanium oxide $\left(\mathrm{N}-\mathrm{TiO}_{2}, D: 22 \mathrm{~nm}\right), \mathrm{N}-\mathrm{TiO}_{2}$ doped with silicon $\left(\mathrm{N}-\mathrm{Si}-\mathrm{TiO}_{2}, D\right.$ : $11 \mathrm{~nm}$ ), which is effective for reducing the defects in $\mathrm{TiO}_{2}$, and $\mathrm{N}-\mathrm{Si}-\mathrm{TiO}_{2}$ deposited with vanadium $\left(\mathrm{V}-\mathrm{N}-\mathrm{Si}-\mathrm{TiO}_{2}, D\right.$ : $13 \mathrm{~nm}),{ }^{36,37}$ for which enhanced photocatalytic ability was reported, were used as visible light photocatalysts. Powder samples were dispersed in a solution using the same method as for the $\mathrm{TiO}_{2}$ powder to prepare a paste. The method for the paste preparation is a general procedure for coating a nanoparticulate inorganic material on a glass. For all materials used here, it was confirmed that the thickness of the coating was $3 \pm 0.5$ microns, but the porosities ranged from 40 to $60 \%$.

We investigated the organic conversion of various molecules due to photocatalytic reactions, and we selected the following reactions as candidates to show the oxidation and reduction 
abilities. To select the reactions, we placed importance on the simplicity of the reactions and easy monitoring of the UV spectra of the reactants and products.

The oxidation of benzyl alcohol (BAlc) to benzaldehyde (BAld $)^{2,5}$ and the reduction of BAld to BAlc were selected, and the reaction schemes are shown in reactions (1) and (2) (Scheme 1). They are the reverse reactions of each other, and they can be controlled simply by changing the solvent: acetonitrile for oxidation and ethanol for reduction. For the oxidation, holes are used as an oxidant. Electrons are used for reduction since ethanol is a good scavenger of photoexcited holes, which prevents the recombination of electrons. ${ }^{\mathbf{1 4 , 3 8}}$ Initially, we chose these reactions because the product analyses by GC and the monitoring of the spectra were easy, as we only had to monitor BAlc and BAld. However, we selected another reduction reaction, the reduction of nitrobenzene $(\mathrm{NB})$ to aniline (AN) (reaction (3), Scheme 1), ${ }^{\mathbf{8}, 14,15}$ due to several reasons which we will explain in the following section.

\section{Results and discussion}

\section{Product analysis}

In the case of a typical photocatalyst, $\mathrm{TiO}_{2}$, the $\mathrm{GC}$ charts for the oxidation of BAlc and the reductions of BAld and NB before and after reactions are shown in Fig. 1. The initial concentrations of the reactant solutions were $1 \mathrm{mM}$. As shown in Fig. 1, all the peak intensities for the reactants decreased after the reactions. For the oxidation reaction, the peak for BAld at 21 min was the only product peak observed, except for the solvent peak. For the reduction reaction, the peak for the corresponding reduced species, BAlc, was observed at $32 \mathrm{~min}$. Several other peaks were observed, corresponding to acetaldehyde and acetic acid due to the oxidation of ethanol. Since we did not observe any peaks except for those of the products and the solvent, no by-products were observed, and we can predict that the other products would be carbon dioxide and water. In the case of the reduction

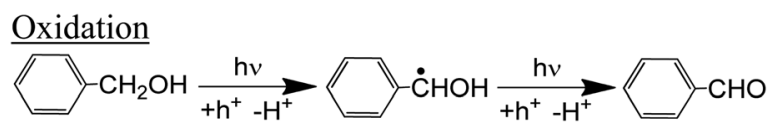

$\underline{\text { Reduction }}$
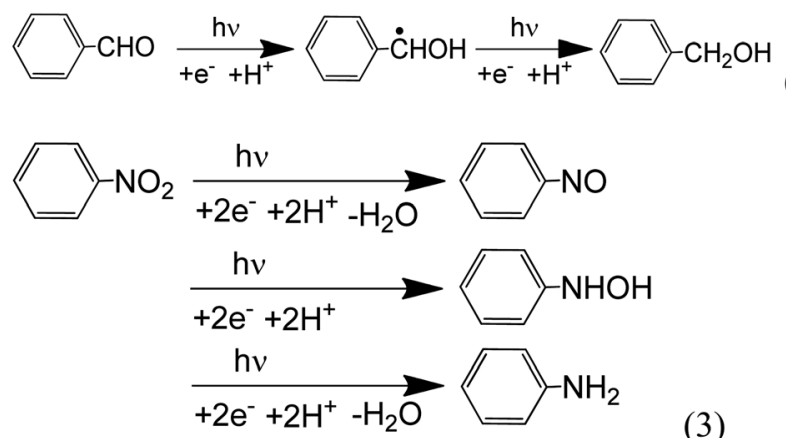

Scheme 1 Reaction candidates for the photocatalytic oxidation and reduction.
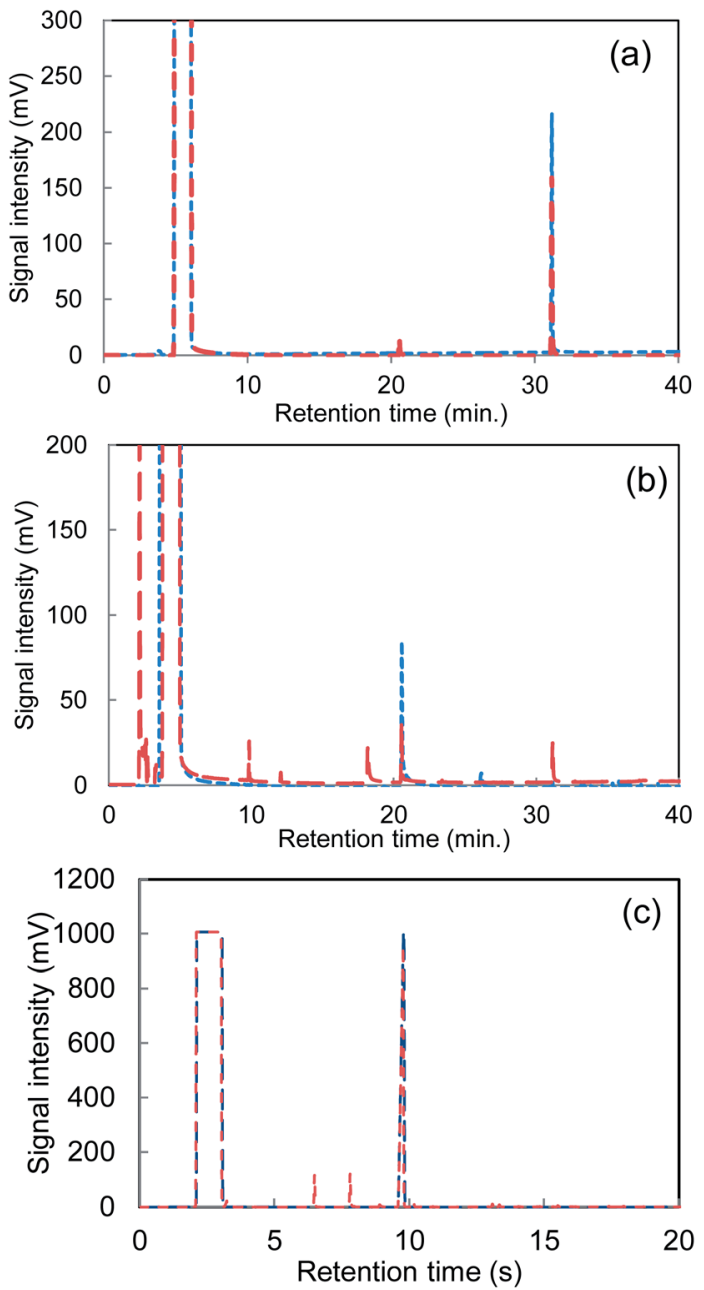

Fig. 1 The GC charts before and after the photocatalytic reactions: (a) oxidation of benzyl alcohol, (b) reduction of benzaldehyde, (c) reduction of nitrobenzene. The blue dotted line and the red dashed line correspond to before and after the reaction, respectively. The reaction time was $18 \mathrm{~h}$ for (1) and (2), and $30 \mathrm{~min}$ for (3).

of NB, the peaks for aniline (AN) at $7.8 \mathrm{~min}$ and nitrosobenzene at $6.5 \mathrm{~min}$ were observed, and the latter is an intermediate species. For this reaction, the light irradiation was only applied for $30 \mathrm{~min}$ because unknown reactions proceeded at longer irradiation times.

The conversions, yields, and selectivities are summarized in Table 1. The conversion values can be used as a guide for estimating how efficiently the photoexcited electrons and holes

Table 1 Conversions, yields and selectivities for the oxidation and reduction reactions in the photocatalytic microreactor: (1) oxidation of benzyl alcohol, (2) reduction of benzaldehyde, (3) reduction of nitrobenzene. The reaction time was $18 \mathrm{~h}$ for (1) and (2), and $30 \mathrm{~min}$ for (3)

\begin{tabular}{llcl}
\hline Entry & Conversion (\%) & Yield (\%) & Selectivity (\%) \\
\hline$(1)$ & 24 & 8 & 33 \\
$(2)$ & 69 & 23 & 33 \\
$(3)$ & 6 & 5 & 77
\end{tabular}


were utilized, namely the total oxidation ability. The selectivities and yields are indicators of how many electrons and holes were used for the intended reactions.

\section{Reaction rate analysis}

Each reaction was monitored in situ using UV absorption spectroscopy. The changes in the spectra with time for the oxidation and reduction reactions are shown in Fig. 2. For the oxidation reaction, $5 \mathrm{mM}$ BAlc/acetonitrile (ACN) was used as a reactant, and the spectrum of BAlc with a peak at $270 \mathrm{~nm}$ gradually decayed and changed into the spectrum of BAld. It was noted that the reaction was almost saturated after about 60 s. From the reference spectra for BAld and BAlc in ACN at certain concentrations, we could fit each spectrum obtained during the reaction to a combination of these reference spectra, and we could obtain the concentrations of BAld and BAlc at each time. (A typical fitted spectrum is shown in Fig. S4. $\dagger$ )

The concentration changes during the reactions are shown in Fig. 3. An increase in the concentration of BAld and a decrease in the concentration of BAlc were confirmed and the change was gradually saturated after about $60 \mathrm{~s}$. It was noted that the sum of the BAld and BAlc concentrations remained at $5 \mathrm{mM}$. This indicated that this reaction proceeded with $100 \%$ selectivity until 60 seconds after the reaction started. We suppose that the reaction was saturated because the product species covered the active reaction sites, since the reactivity was recovered by replacement of the solution.

Furthermore, the concentrations of BAld and BAlc showed linear changes with time, and this indicated that this reaction is zeroth order, which can be explained by the rate analysis of the surface reaction (see Appendix). Since the reaction became saturated as it proceeded, the straight parts of the concentration curves were used to analyse the data. We successfully obtained a reaction rate constant of $0.011 \mathrm{~mol} \mathrm{~L}^{-1} \mathrm{~s}^{-1}$.

Similarly, the reduction of BAld was monitored as shown in Fig. 2(b). The reduction did not proceed until $60 \mathrm{~s}$ after the photoirradiation, and the concentration of BAld suddenly decreased after that. We tried fitting the spectrum in a similar way as for the oxidation reaction, but it was very difficult to obtain the exact concentration of BAlc because the absorption intensity of BAld is much stronger than that of BAlc for the same concentration, therefore the contribution of BAlc to the spectrum was difficult to deduce, and the error was very large for the smaller concentration of BAlc, as shown in Fig. 3(b). (It is noted that the absorbances of BAld and BAlc in Fig. 2(a and b) were different because of the different solvents.) Since it is still unclear why there was a lag time for the start of the reaction and the accuracy of the BAlc concentration was not good enough, we selected another reaction for the reduction reaction.

Then, we used the conversion of NB to AN, which is a wellknown reduction reaction that proceeds via photocatalysis. The peak at $270 \mathrm{~nm}$, corresponding to $\mathrm{NB}$, gradually decayed and a new peak at $250 \mathrm{~nm}$ appeared. The reaction was saturated after approximately $100 \mathrm{~s}$. However, the spectrum of the product did not perfectly match that of AN, which shows a peak at approximately $240 \mathrm{~nm}$.
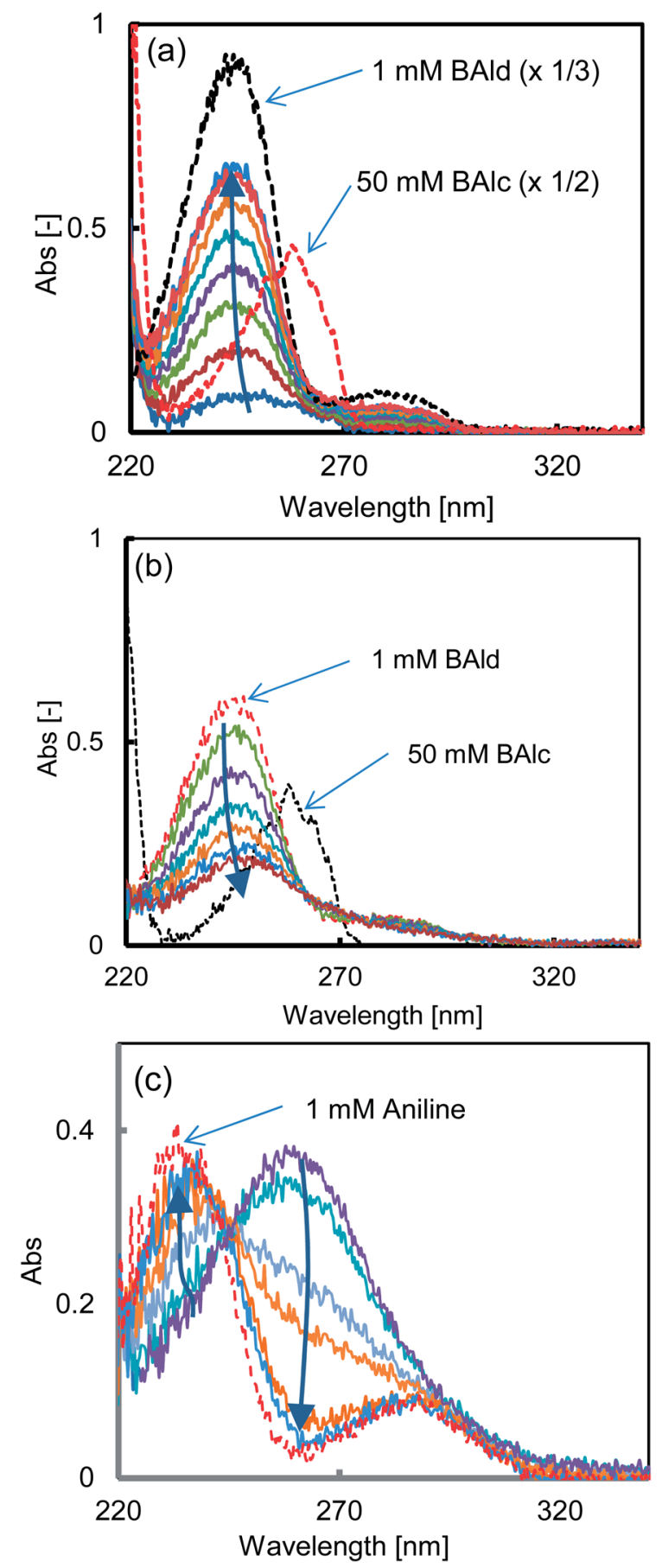

Fig. 2 Absorption spectra for the oxidation and reduction reactions observed directly in a photocatalytic microreactor. (a) corresponds to the oxidation of benzyl alcohol. The spectra obtained $0,10,20,30,40$, 50,60 and $80 \mathrm{~s}$ after the reaction was started by UV irradiation are shown. The dotted lines indicate the reference spectra for benzyl alcohol and benzaldehyde. (b) corresponds to the reduction of benzaldehyde. The spectra obtained 0, 80, 100,120,140, 160 and $175 \mathrm{~s}$ after the reaction started are shown. The dotted lines indicate the reference spectra for benzyl alcohol and benzaldehyde. It is noted that the absorbances are different in (a) and (b) because of the different solvents used. (c) corresponds to the reduction of nitrobenzene. The spectra obtained $0,20,40,60,80$ and $100 \mathrm{~s}$ after the reaction started are shown. The dotted line indicates the reference spectrum for aniline. 

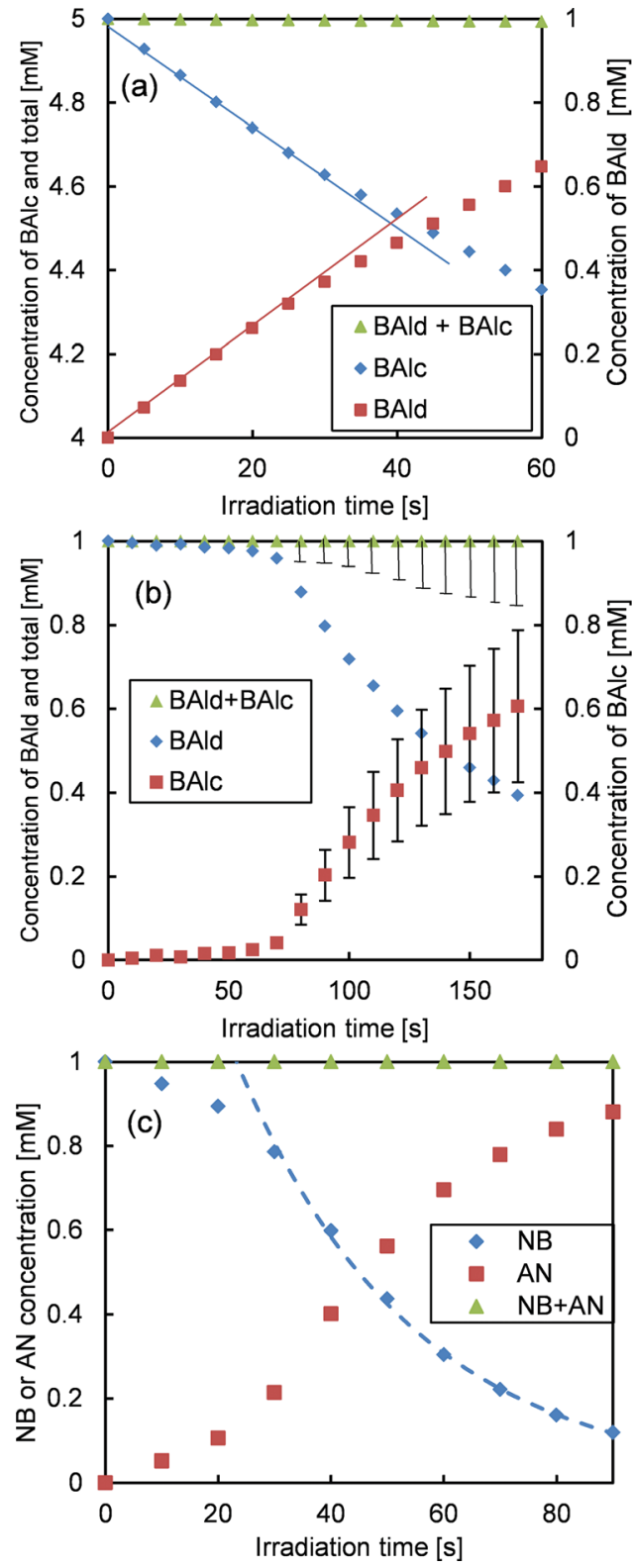

Fig. 3 Changes in the reactant and product concentrations with time for the oxidation and reduction reactions in the photocatalytic microreactors: (a) the oxidation reaction of benzyl alcohol, (b) the reduction reaction of benzaldehyde, (c) the reduction reaction of nitrobenzene. Fitting curves for BAlc and BAld in (a) and for NB in (c) were obtained by analysis of the $0^{\text {th }}$ order and $1^{\text {st }}$ order kinetics, respectively.

We suspected that $\mathrm{AN}$ was subject to photoreaction, and thus the change in the spectrum of AN on irradiation with UV light was monitored. Actually, the peak in the spectrum shifted from 240 to $250 \mathrm{~nm}$ and the resulting spectrum agreed well with the spectrum of the product of the NB reduction. The product was an imine compound, as confirmed by the GC-MS analysis ( $N$-ethylideneaniline). Thus, it was considered that AN was generated in the reduction of NB but that the generated AN was changed into the imine compound by reacting with the acetaldehyde generated via the oxidation of ethanol.
However, we found out that AN did not react when 2-propanol was used as a solvent, probably because the oxidized molecule, acetone, did not react with AN. The absorption spectra for the reduction of NB in 2-propanol are shown in Fig. 2(c), and we could successfully observe the pure reduction reaction of NB to AN. The spectra obtained during the reaction were fully fitted to combinations of the AN and NB spectra (Fig. S4(c) †). The concentration change during the reaction is shown in Fig. 3(c). We observed that the reaction started after 10-20 s, which was much shorter than the corresponding time for the reduction of BAld, and the lag time was reproducible as long as $\mathrm{TiO}_{2}$ was used. Neglecting the lag time, the concentration change corresponded to a $1^{\text {st }}$ order reaction, as shown in Fig. 3(c), and a reaction rate of $0.032 \mathrm{~s}^{-1}$ was obtained. (It is noted that this value is the reaction rate multiplied by the adsorption equilibrium constant. See Appendix.)

\section{Application of the screening methods for visible light photocatalysts}

An evaluation of several visible light photocatalysts using the oxidation and reduction reactions was performed. The following photocatalysts were analysed: $\mathrm{WO}_{3}$ and $\mathrm{N}-\mathrm{TiO}_{2}$ as typical visible light photocatalysts, $\mathrm{N}-\mathrm{TiO}_{2}$ doped with silicon $\left(\mathrm{N}-\mathrm{Si}-\mathrm{TiO}_{2}\right)$, which is effective for reducing the defects in $\mathrm{TiO}_{2}{ }^{36}$ and $\mathrm{N}-\mathrm{Si}-\mathrm{TiO}_{2}$ deposited with vanadium $\left(\mathrm{V}-\mathrm{N}-\mathrm{Si}-\mathrm{TiO}_{2}\right)$, for which an enhanced photocatalytic activity was reported. ${ }^{37}$

The results for the oxidation reaction of BAlc are shown in Table 2. The corresponding results for $\mathrm{TiO}_{2}$ under UV irradiation of similar intensity are shown too. Overall, the oxidation abilities of the visible light photocatalysts were comparable to that of $\mathrm{TiO}_{2}$ under UV illumination, considering differences in the light intensity and the absorbance of the materials, etc. $\mathrm{WO}_{3}$ showed the highest conversion, but the selectivity was quite low. With regard to the $\mathrm{Si}$ doping, $\mathrm{N}-\mathrm{Si}-\mathrm{TiO}_{2}$ showed higher conversion and selectivity compared with $\mathrm{N}^{-\mathrm{TiO}_{2}}$. Vanadium deposition gave a lower efficiency for the oxidation. The results for the reduction reaction of BAld are shown in Table 3. Compared with $\mathrm{TiO}_{2}$, the reduction abilities of the visible light photocatalysts were quite low on the whole, and no reduction product was observed for $\mathrm{WO}_{3}$, which can be explained by the low conduction band position. For the visible light photocatalysts, $\mathrm{N}-\mathrm{Si}-\mathrm{TiO}_{2}$ showed the highest conversion and selectivity, and vanadium deposition lowered the reaction efficiency.

Table 2 Conversions, yields and selectivities for the oxidation of benzyl alcohol in the photocatalytic microreactor for various photocatalytic materials

\begin{tabular}{|c|c|c|c|}
\hline Entry & Conversion (\%) & Yield (\%) & Selectivity (\%) \\
\hline $\mathrm{TiO}_{2}$ with UV & 17 & 3.7 & 22 \\
\hline $\mathrm{WO}_{3}$ & 25 & 0.3 & 1.0 \\
\hline $\mathrm{N}-\mathrm{TiO}_{2}$ & 7.5 & 3.7 & 49 \\
\hline $\mathrm{N}-\mathrm{Si}-\mathrm{TiO}_{2}$ & 14 & 8.1 & 56 \\
\hline $\mathrm{V}-\mathrm{N}-\mathrm{Si}-\mathrm{TiO}_{2}$ & 8.8 & 5.6 & 56 \\
\hline
\end{tabular}


Table 3 Conversions, yields and selectivities for the reduction of benzaldehyde in the photocatalytic microreactor for various photocatalytic materials

\begin{tabular}{|c|c|c|c|}
\hline Entry & Conversion (\%) & Yield (\%) & Selectivity (\%) \\
\hline $\mathrm{TiO}_{2}$ with UV & 51 & 17 & 17 \\
\hline $\mathrm{WO}_{3}$ & 8.3 & 0 & 0 \\
\hline $\mathrm{N}-\mathrm{TiO}_{2}$ & 14 & 2.4 & 17 \\
\hline $\mathrm{N}-\mathrm{Si}-\mathrm{TiO}_{2}$ & 18 & 5.2 & 29 \\
\hline $\mathrm{V}-\mathrm{N}-\mathrm{Si}-\mathrm{TiO}_{2}$ & 12 & 1.6 & 13 \\
\hline
\end{tabular}

Table 4 Reaction rates for the BAlc oxidation measured by direct UV monitoring in the photocatalytic microreactor

\begin{tabular}{ll}
\hline Entry & $\begin{array}{l}\text { Conversion reaction } \\
\text { rate }\left(\times 10^{-3} \mathrm{~mol} \mathrm{~L}^{-1} \mathrm{~s}^{-1}\right)\end{array}$ \\
\hline $\mathrm{WO}_{3}$ & 0.440 \\
$\mathrm{~N}-\mathrm{TiO}_{2}$ & 0.298 \\
$\mathrm{~N}-\mathrm{Si}-\mathrm{TiO}_{2}$ & 0.214 \\
$\mathrm{~V}-\mathrm{N}-\mathrm{Si}-\mathrm{TiO}_{2}$ & 0.160
\end{tabular}

A reaction rate analysis was performed for the visible light photocatalysts. Since they showed very low reduction abilities, we studied only the BAlc oxidation reaction, which proceeded with almost $100 \%$ selectivity even for the visible light photocatalysts. The changes in the reactant and product concentrations with time are shown in Fig. S5 in the ESI. $\uparrow$ The obtained reaction rates are listed in Table 4 .

From the product analysis and reaction rate analysis, the oxidation ability of $\mathrm{WO}_{3}$ was high, although the reaction was not selective. There was a discrepancy between the product analysis and reaction rate analysis for the oxidation abilities of $\mathrm{N}-\mathrm{TiO}_{2}$ and $\mathrm{N}-\mathrm{Si}-\mathrm{TiO}_{2}$. This is probably because $\mathrm{N}-\mathrm{TiO}_{2}$ lost its reactivity during the long reaction time, while the initial reaction rate was large during the reaction rate analysis carried out within a few minutes. Basically, it can be said that Si doping in $\mathrm{TiO}_{2}$ is effective for enhancing both the oxidation and reduction reactivities due to the decrease in the internal defects. But we could not confirm the enhancement of the reaction efficiency by vanadium deposition, because both the oxidation and reduction reactions were deactivated. This is probably because the deposition would reduce the number of active reaction sites.

\section{Conclusion}

We developed two analytical methods for the evaluation of photocatalytic materials using a photocatalytic microreactor; one method is product analysis and the other is reaction rate analysis. To perform a simple analysis of the photocatalytic abilities, we selected oxidation and reduction reactions of organic compounds, which are easily monitored by GC and absorption spectra due to the one-to-one reactions. We could establish the methods of product analysis and reaction rate analysis, and they were applied to several visible light photocatalysts. It is expected that this novel analytical procedure could accelerate the development of new materials which are very useful for various purposes.

\section{Appendix}

Whether the reaction is zeroth or first order is determined by analysis of the rate equation for the surface reaction. We consider the following reactions at the surface:

$$
\begin{gathered}
\mathrm{A}+\sigma \underset{k_{\mathrm{A}}^{\prime}}{\stackrel{k_{\mathrm{A}}}{\rightleftarrows}} \mathrm{A} \sigma \\
\mathrm{A} \sigma \stackrel{k_{\mathrm{r}}}{\longrightarrow} \mathrm{C} \sigma
\end{gathered}
$$

where $\mathrm{A}$ and $\mathrm{C}$ are the reactant and product, respectively, and $\sigma$ is the active reaction site. The reaction rates for (4) and (5) are written as follows:

$$
\begin{gathered}
r_{1}=k_{\mathrm{A}}[\mathrm{A}] \theta_{\mathrm{V}}-k_{\mathrm{A}}^{\prime} \theta_{\mathrm{A}} \\
r_{2}=k_{\mathrm{r}} \theta_{\mathrm{A}}
\end{gathered}
$$

where $\theta_{\mathrm{V}}$ and $\theta_{\mathrm{A}}$ are the vacancy ratio and the ratio occupied by $\mathrm{A}$ species on the surface, respectively, and [A] is the concentration of $\mathrm{A}$ in the liquid phase. It is assumed that the reaction rate of (6) is fast under equilibrium, and $K_{\mathrm{A}}=k_{\mathrm{A}} / k_{\mathrm{A}}^{\prime}$ is defined as an adsorption equilibrium constant. The reaction rate for the whole reaction is assumed to be $r_{2}$, and it is written as follows:

$$
r_{2}=\frac{k_{\mathrm{r}} K_{\mathrm{A}}[\mathrm{A}]}{1+K_{\mathrm{A}}[\mathrm{A}]} .
$$

When $K_{\mathrm{A}}[\mathrm{A}] \ll 1, \mathrm{r}_{2}$ is approximated as $k_{\mathrm{r}} K_{\mathrm{A}}[\mathrm{A}]$, and when $K_{\mathrm{A}}[\mathrm{A}] \gg 1$, it is approximated as $k_{\mathrm{r}}$. The latter condition was satisfied for the oxidation of BAlc, and the former was satisfied for the reduction of NB.

\section{Notes and references}

1 N. Serpone, E. Pelizzetti and H. Hidaka, Photocatalytic Purification and Treatment of Water and Air, Elsevier, London, 1993.

2 C. J. Li, G. R. Xu, B. H. Zhang and J. R. Gong, Appl. Catal., B, 2012, 115-116, 201-208.

3 P. Ciambelli, D. Sannino, V. Palma and V. Vaiano, Catal. Today, 2005, 99, 143-149.

4 K. Imamura, H. Tsukahara, K. Hamamichi, N. Seto, K. Hashimoto and H. Kominami, Appl. Catal., A, 2013, 450, 28-33.

5 S. Yurdakal and V. Augugliaro, RSC Adv., 2012, 2, 8375-8380. 6 J. T. Carneiro, A. R. Almeida, J. A. Moulijn and G. Mul, Phys. Chem. Chem. Phys., 2010, 12, 2744-2750.

7 O. S. Mohamed, A. M. Gaber and A. A. Abdel-Wahab, J. Photochem. Photobiol., A, 2002, 148, 205-210.

8 K. Imamura, T. Yoshikawa, K. Hashimoto and H. Kominami, Appl. Catal., B, 2013, 134-135, 193-197.

9 A. Maldotti, L. Andreotti, A. Molinari, S. Tollari, A. Penoni and S. Cenini, J. Photochem. Photobiol., A, 2000, 133, 129-133.

10 V. Brezová, A. Blažková, I. Šurina and B. Havlínová, J. Photochem. Photobiol., A, 1997, 107, 233-237.

11 Y. Shiraishi and T. Hirai, J. Photochem. Photobiol., C, 2008, 9, 157-170. 
12 H. Yoshida, Photocatalytic Organic Synthesis, Springer, New York, 2010.

13 V. Augugliaro, T. Caronna, A. D. Paola, G. Marci, M. Pagliaro, G. Palmisano and L. Palmisano, $\mathrm{TiO}_{2}$-Based Photocatalysis for Organic Synthesis, Springer, New York, 2010.

14 S. O. Flores, O. Rios-Bernij, M. A. Valenzuela, I. Cordova, R. Gomez and R. Gutierrez, Top. Catal., 2007, 44, 507-511.

15 J. L. Ferry and W. H. Glaze, Langmuir, 1998, 14, 35513555.

16 O. Rios-Berny, S. O. Flores, I. Cordova and M. A. Valenzuela, Tetrahedron Lett., 2010, 51, 2730-2733.

17 K. Selvam and M. Swaminathan, Tetrahedron Lett., 2010, 51, 4911-4914.

18 K. Selvam and M. Swaminathan, Catal. Commun., 2011, 12, 389-393.

19 R. Abe, J. Photochem. Photobiol., C, 2010, 11, 179-209.

20 S. I. Allakhverdiev, V. Thavasi, V. D. Kreslavski, S. K. Zharmukhamedov, V. V. Klimov, S. Ramakrishna, D. A. Los, M. Mimuro, H. Nishihara and R. Carpentier, J. Photochem. Photobiol., C, 2010, 11, 101-113.

21 K. Maeda, J. Photochem. Photobiol., C, 2011, 12, 237-268.

22 Y. Han, H. S. Kim and H. Kim, J. Nanomater., 2012, 2012, 110.

23 S. I. In and R. Berg, Asian J. Chem., 2012, 24, 428-432.

24 Z. Liu, X. Zhang, S. Nishimoto, T. Murakami and A. Fujishima, Environ. Sci. Technol., 2008, 42, 8547-8551.

25 M. Mori, K. Tanaka, H. Taoda, M. Ikedo and H. Itabashi, Talanta, 2006, 70, 169-173.
26 N. Tsuchiya, K. Kuwabara, A. Hidaka, K. Oda and K. Katayama, Phys. Chem. Chem. Phys., 2012, 14, 4734-4741.

27 N. Wang, Y. P. Zhang, L. Lei, H. L. W. Chan and X. M. Zhang, in Nems/Mems Technology and Devices, 2011, vol. 254, pp. 219-222.

28 Y. Matsushita, N. Ohba, S. Kumada, T. Suzuki and T. Ichimura, Catal. Commun., 2007, 8, 2194-2197.

29 Y. Matsushita, M. Iwasawa, T. Suzuki and T. Ichimura, Chem. Lett., 2009, 38, 846-847.

30 Y. Matsushita, S. Kumada, K. Wakabayashi, K. Sakeda and T. Ichimura, Chem. Lett., 2006, 35, 410-411.

31 R. Gorges, S. Meyer and G. Keisel, J. Photochem. Photobiol., A, 2004, 167, 95-99.

32 E. E. Coyle and M. Oelgemoller, Photochem. Photobiol. Sci., 2008, 7, 1313-1322.

33 N. M. Mahmoodi, M. Arami, N. Y. Limaee and N. S. Tabrizi, Chem. Eng. J., 2005, 112, 191-196.

34 I. K. Konstantinou and T. A. Albanis, Appl. Catal., B, 2004, 49, 1-14.

35 K. Katayama, Y. Takeda, K. Kuwabara and S. Kuwahara, Chem. Commun., 2012, 48, 7368-7370.

36 A. Mase, T. Sugita, M. Mori, S. Iwamoto, T. Tokutome, K. Katayama and H. Itabashi, Chem. Eng. J., 2013, 225, 440-446.

37 A. Maldotti and A. Molinari, in Photocatalysis, 2011, vol. 303, pp. 185-216.

38 A. I. Kryukov, S. Y. Kuchmy, S. V. Kulik and A. V. Korzhak, Theor. Exp. Chem., 1992, 28, 416-419. 